\title{
COMPARATIVE, OSTEOCHONDRAL DEFECT REPAIR: STEM CELLS VERSUS CHONDROCYTES VERSUS BONE MORPHOGENETIC PROTEIN-2, SOLELY OR IN COMBINATION
}

\author{
R. Reyes, M.K. Pec, E. Sánchez, C. del Rosario, A. Delgado and C. Évora* \\ Department of Chemical Engineering and Pharmaceutical Technology. University of La Laguna. La Laguna, \\ Tenerife, Spain.
}

\begin{abstract}
Full-thickness articular cartilage damage does not resolve spontaneously. Studies with growth factors, implantation of autologous chondrocytes and mesenchymal stem cells have led to variable, to some extent inconsistent, results. This work compares osteochondral knee-defect repair in rabbits upon implantation of a previously described alginate/ (poly(lactic-co-glycolic) acid (PLGA) osteochondral scaffold in distinct conditions. Systems were either in vitro pre-cultured with a small number of allogeneic chondrocytes under fibroblast growth factor (FGF)-2 stimulation or the same amount of allogeneic, marrow derived, mesenchymal stem cells (without any pre-differentiation), or loaded with microsphere-encapsulated bone morphogenetic protein (BMP)-2 within the alginate layer, or holding combinations of one or the other cell type with BMP-2. The experimental limit was 12 weeks, because a foregoing study with this release system had shown a maintained tissue response for at least 24 weeks post-operation. After only 6 weeks, histological analyses revealed newly formed cartilage-like tissue, which resembled the adjacent, normal cartilage in cell as well as BMP-2 treated defects, but cell therapy gave higher histological scores. This advantage evened out until 12 weeks. Combinations of cells and BMP-2 did not result in any additive or synergistic effect. Equally efficient osteochondral defect repair was achieved with chondrocyte, stem cell, and BMP-2 treatment. Expression of collagen $X$ and collagen I, signs of ongoing ossification, were histologically undetectable, and the presence of aggrecan protein indicated cartilage-like tissue. In conclusion, further work should demonstrate whether spatiotemporally controlled, on-site BMP-2 release alone could become a feasible therapeutic approach to repair large osteochondral defects.
\end{abstract}

Keywords: Cartilage repair; osteochondral defect; chondrocytes; bone marrow derived mesenchymal stem cells; BMP-2; controlled release; scaffold; alginate/PLGA; rabbit; histology.

* Address for correspondence:

C. Évora

Department of Chemical Engineering and Pharmaceutical Technology

University of La Laguna

Avda. Astrofísico Fco. Sánchez

38200 La Laguna, Tenerife, Spain.

Telephone Number: +34922318597

FAX Number: +34922318506

E-mail: cevora@ull.es

\section{Introduction}

Local chondral and osteochondral defects affect millions of people worldwide and represent a considerable challenge for the orthopaedic community. Activity of chondrocytes, the only resident cells in cartilage, determines tissue properties. The avascular nature of cartilage implies that oxygen and nutrient supply depend on diffusion from surrounding tissues leading to slow cell proliferation and a reduced regenerative competence.

Cell-based strategies are increasingly explored to provide biological replacement of the damaged tissue, either by implantation of in vitro generated, chondral or osteochondral grafts or chondrocytes, which are, then, stimulated in vivo.

Clinically applied, operative techniques like abrasion arthroplasty, subchondral drilling, microfracturing, autologous matrix-induced chondrogenesis (Jacobi et al., 2011), and mosaicplasty (autologous, osteochondral cylinder-replacement) frequently face drawbacks either by the formation of fibrocartilage rather than hyaline cartilage (Grässel and Anders, 2012) or limited donor site availability or morbidity and poor edge integration (Khan et al., 2010).

Implantation of autologous chondrocytes (first generation ACI) (Brittberg et al., 1994) and chondrocyteloaded, mainly collagen matrices (second generation ACI) (Bartlett et al., 2005) are also in clinical use but require two interventions and, according to recent reviews, result only in short-term and medium-term success (Harris et al., 2010). Alternatively, mesenchymal stem cells (MSCs) of bone marrow, adipose tissue or embryonic origin (Hellingman et al., 2012) are currently investigated for cartilage defect repair. Key issues in terms of long-term functional tissue comprise the inhibition of terminal differentiation and maintenance of a stable cartilaginous phenotype (Grässel and Anders, 2012).

Procedures for cartilage defect repair still need perfecting, e.g., by introducing cell-seeded biomaterial scaffolds or growth factors (GFs) that mimic physiological stimuli, enhance cell proliferation and warrant adequate differentiation, thus avoiding hypertrophic maturation and osteogenic induction in chondrocytes and GF induced chondrogenesis of MSCs (Claus et al., 2010; Freyria and Mallein-Gerin, 2012).

Within the group of GFs involved in cartilage repair (Schmal et al., 2009; Fortier et al., 2011), members of the tumour growth factor (TGF)- $\beta$ superfamily are known to restore and maintain the chondrogenic phenotype and induce MSC chondrogenesis in vitro (Gouttenoire et al., 2010, Freyria and Mallein-Gerin, 
2012). Accordingly, scaffolds may be loaded with GFs such as bone morphogenetic protein (BMP)-2 and TGF- $\beta 1$ (Sellers et al., 1997; Sellers et al., 2000; Holland et al., 2005; Holland et al., 2007; Reyes et al., 2012), seeded with chondrocytes or MSCs (Guo et al., 2010; Qi et al., 2011; Ito et al., 2012), or employed with combinations of both GFs and cells (Im and Lee, 2010; Wang et al., 2010).

To date, only few studies compare MSCs and chondrocytes in cartilage defect repair. Yan and $\mathrm{Yu}$ (2007) observed no significant in vivo difference between histological scores from osteochondral defects implanted either with MSCs or chondrocytes on PLA porous scaffolds. Dashtdar et al. (2011) compared the efficacy of MSCs, in vitro differentiated into chondrocytes, and undifferentiated MSCs, both encapsulated in alginate beads, on full-thickness cartilage defect repair in rabbits. However, both treatments resulted in equally superior healing compared to untreated defects.

The frequently varying outcomes of cartilage repair from cell implantation approaches are likely the consequence of different cell sources and differentiation strategies, growth factor (GF) liberation patterns, scaffold properties, model-specific defect environments, and the animal model itself. A few clinical studies have already demonstrated the advantage of GF presentation via material carriers over systemic or local bolus application (Kangwon et al., 2011). On the whole, the complex in vivo healing environment requires further understanding of GF interactions to decide on the most appropriate approach in view of a stable clinical outcome.

Here, we hypothesised that an improved defect environment, provided by implanted cells, timely correlated stimulating signals from the scaffold, the adjacent cartilage and the subchondral bone may be the key to optimise in situ cartilage repair. This study compares osteochondral defect repair in rabbits upon implantation of allogeneic chondrocyte- versus MSC-seeded, alginate/ PLGA tri-layer scaffolds, both without BMP-2 and under controlled release of the alginate-embedded, microsphereencapsulated BMP-2. A relatively low dose of $5 \mu \mathrm{g}$ of BMP-2 and its release kinetics from this system had been optimised for cartilage repair in a preceding study (Reyes et al., 2012). BMP-2 was liberated into the defect for approximately 6 weeks (previously determined by local ${ }^{125}$ I-BMP-2 monitoring). In the foregoing study, the morphologically cartilage-like tissue observed 12 weeks post-implantation was maintained at least until the 24th week. The present study was limited to compare an early cartilage repair response to the proposed implantation strategies.

\section{Materials and methods}

\section{Preparation of the tri-layered scaffold}

The scaffold (Fig. 1a) was prepared as previously described (Reyes et al., 2012). Briefly, the bone-directed layer (Fig. 1b) was fabricated by gas foaming in an acidic aqueous solution. (Poly(lactic-co-glycolic) acid (PLGA) (50:50) (Resomer ${ }^{\circledR}$ RG504, Boehringer-Ingelheim, Barcelona, Spain) in acetone was mixed with particles of ammonium bicarbonate salt (3:1) to form a paste, which was introduced into a polyethylene syringe and subsequently pressed out into citric acid solution, where it was kept for 4 days. Thereafter, the cylinders were rinsed, freeze-dried, and maintained at $4{ }^{\circ} \mathrm{C}$ in cylindrical moulds $(4.5 \mathrm{~mm}$ internal diameter) until use.

A bilayered, osteochondral scaffold was assembled in the mould holding the PLGA porous structure. To this end, $6 \mathrm{mg}$ of blank PLGA microspheres or $6 \mathrm{mg}$ of BMP-2 $(5 \mu \mathrm{g})$ (Biomedal, Sevilla, Spain), dispersed in $20 \mu \mathrm{L}$ of a $1.5 \%$ alginate aqueous solution (Pronova UPCL, Lysaker, Norway), were introduced into the mould, cross-linked with a $\mathrm{CaCl}_{2}$ solution $(0.73 \%)$, and freeze-dried (Fig. 1c). The third layer was similar to the second one, except for containing $4 \mathrm{mg}$ of blank microspheres, and was prepared separately. This layer was used for cell seeding (Fig. 1d).

The volume diameter $(\mu \mathrm{m})$ distribution of the ammonium bicarbonate salt particles, previously pulverised and sieved, was $158 \pm 76 \mu \mathrm{m}$, measured in acetone (Mastersizer 2000 with Hydro 2000 SM, Malvern Instruments, Malvern, UK).

\section{Microsphere preparation}

BMP-2 loaded microspheres were prepared by a double emulsion (w/o/w) method (Hernández et al., 2012). Briefly, the first emulsion was made by vortexing $200 \mu \mathrm{L}$ of a BMP-2 $(180 \mu \mathrm{g})$ solution in $0.07 \%$ poly-vinyl alcohol (PVA) with 2 mL of a PLGA (Resomer ${ }^{\circledR}$ RG504) methylene chloride solution $(50 \mathrm{mg} / \mathrm{mL})$. Then, it was poured into a $0.1 \%$ PVA (w/v) aqueous solution under constant stirring and kept until the organic solvent had evaporated $(2 \mathrm{~h})$. Microspheres were isolated by filtration and freeze-dried.

\section{Cells}

To avoid multiple interventions in one animal, cells from healthy New Zealand white rabbits, both marrow derived MSCs as well as chondrocytes, were isolated from another individual from the same litter (6 months of age) as the animal to be implanted. Both cell types were expanded in logarithmic growth phase and subcultured at approximately $80 \%$ of confluence. Expanded cells were frozen for later experimental use. Unless otherwise specified, all cell culture material was from PAA (Linz, Austria) and culture plastic from Nunc (Langenselbold, Germany).

\section{Rabbit bone marrow stem cell (rbMSC) isolation and culture}

A spinal needle (Polymedic ${ }^{\circledR}$, Barcelona, Spain) was used with an introducer of $25 \mathrm{G}$ and $103 \mathrm{~mm}$ of length and an inner needle of $21 \mathrm{G}$ and $38 \mathrm{~mm}$ of length; the latter was fastened to a $10 \mathrm{~mL}$ syringe to collect the aspirate, which was immediately transferred to a sterile centrifuge tube with $5 \mathrm{~mL}$ of complete culture medium, supplemented with $100 \mathrm{UI} / \mathrm{mL}$ of heparin. The solution was subsequently diluted with pre-warmed phosphate buffered saline (PBS) and allowed to stand for about $10 \mathrm{~min}$. Thereafter, the separated fat layer was aspirated. Mononuclear cells were collected following density gradient centrifugation (Biocoll, Cultek, Madrid, Spain) at $300 \mathrm{~g}$ for $30 \mathrm{~min}$. Following a wash step with PBS, cells were seeded on culture plastic in complete medium, composed of 


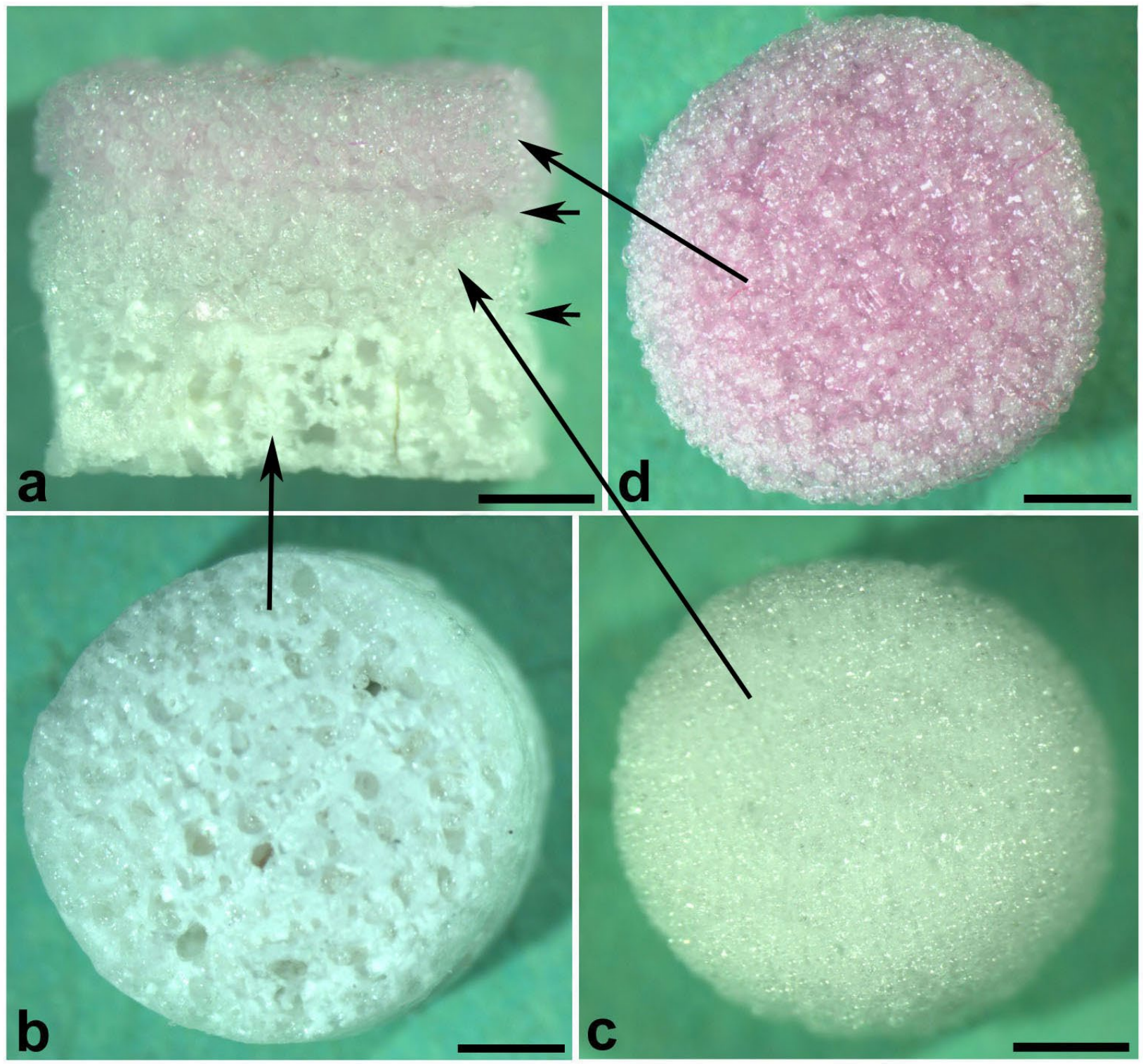

Fig. 1. Tri-layered alginate/PLGA scaffold for osteochondral defect repair. (a) Cross-section exposing the 3 layers. (b) Porous, bone-directed PLGA layer. (c) Cross-linked alginate/PLGA microsphere layer for BMP-2 loading. (d) Cartilage-directed, cross-linked alginate/PLGA microsphere layer for cell seeding. This layer was intentionally dyed to distinguish between the 2 alginate/PLGA microsphere layers. Scale bars $=1 \mathrm{~mm}$.

Dulbecco's modified Eagle's medium (DMEM) (4.5 g/L glucose), $20 \%$ foetal bovine serum (FBS), penicillinstreptomycin, and stabilised L-glutamine. After $5 \mathrm{~d}$, floating cells were removed by a gentle rinse with PBS. Medium was then changed every 3-4 d. Cultures were split by a short incubation of 4 min with trypsin/EDTA (1:250), which favoured selective detachment of mesenchymal cells and left behind phagocytic cells. Two expansion-split steps were necessary to get rid of the contaminating cells.

\section{Rabbit chondrocyte $(r b C)$ isolation and culture}

Cell isolation and culture were performed as described by Pec et al. (2010). Briefly, cartilage slices were aseptically chopped off with a scalpel from knee joints of sacrificed, healthy New Zealand white rabbits. Slices were incubated in $0.05 \%$ trypsin/EDTA $(1: 250)$ in a shaking water bath at $37^{\circ} \mathrm{C}$ and $50 \mathrm{rpm}$ for $15 \mathrm{~min}$. The pellet, resulting from centrifugation at $500 \mathrm{~g}$ for $5 \mathrm{~min}$, was resuspended in a collagenase IV (Sigma, St. Louis, MO, USA) solution at $1 \mathrm{mg} / \mathrm{mL}$ in DMEM (4.5 g/L glucose), supplemented with $10 \%$ FBS ("FCS Gold", PAA, Linz, Austria), and incubated for $150 \mathrm{~min}$ as before. After a short precipitation of the remaining tissue, the supernatant was centrifuged at $500 \mathrm{~g}$ for $5 \mathrm{~min}$ and the resuspended pellet seeded in DMEM, supplemented with $10 \% \mathrm{FBS}, 110 \mathrm{mg} / \mathrm{L}$ sodium-pyruvate (BioWhittaker, Walkersville, MD, USA), penicillin-streptomycin, and stabilised L-glutamine on cell culture plastic. Medium was changed every 3-4 d.

\section{Scaffold-layer cell loading and treatment}

Stock frozen rbMSCs were thawed, precultured on culture plastic for 3-4 d, and trypsin-detached for scaffold loading. The third scaffold layer, allocated for rbMSCs, was incubated overnight at $4{ }^{\circ} \mathrm{C}$ in pure $\mathrm{FBS}$ 
and subsequently centrifuged on nylon meshes of $100 \mu \mathrm{m}$ pore size (Becton Dickinson, San Jose, CA, USA) at $100 \mathrm{~g}$ for $2 \mathrm{~min}$ to eliminate liquid excess. These scaffold layers were transferred to bacterial Petri dishes, and $10 \mu \mathrm{L}$ of the rbMSCs in passage 3 , containing $2 \times 10^{6}$ cells $/ \mathrm{mL}$, were pipetted onto each of them and then incubated at $37{ }^{\circ} \mathrm{C}$ in a $\mathrm{CO}_{2}$ incubator for $90 \mathrm{~min}$ to allow cell adhesion. Subsequently, cell-loaded scaffold layers were cultured in 24-wells with $1 \mathrm{~mL}$ of complete culture medium for $5 \mathrm{~d}$ at $37^{\circ} \mathrm{C}$. Medium was changed after $3 \mathrm{~d}$.

Loading with $2 \times 10^{6} \mathrm{rbCs} / \mathrm{mL}$ in passage 3 was carried out similarly except for skipping the FBS treatment. In addition, the culture medium for rbC-loaded scaffold layers was supplemented with $10 \mathrm{ng} / \mathrm{mL}$ of recombinant, human FGF-2 (Chemicon/Millipore, Billerica, MA, USA), which was renewed with the change of the medium. Again, cells were expanded on the alginate/PLGA microsphere layers for $5 \mathrm{~d}$ in 24-wells.

A total of 13 scaffold layers per cell type were seeded, designated to implantation (6), viable cell quantification (4), and determination of dead cells (3) for each of the two rounds of surgery.

Before implantation, all scaffold layers were washed twice with pre-warmed $\left(37^{\circ} \mathrm{C}\right)$, physiological salt solution (Laboratorios ERN, Barcelona, Spain) and then transferred in renewed salt solution to the operating room.

\section{Propidium iodide (PI) staining}

Dead cells were distinguished in 3 individual control scaffold layers by spontaneous PI (4 mg/mL in PBS) uptake.

On the other hand, all scaffold-adhered cells were visualised by PI staining. To this end, the 4 scaffold layers, previously used for XTT cell quantification, were rinsed with PBS and fixed in formaldehyde $\left(4 \%\right.$ in PBS) at $4{ }^{\circ} \mathrm{C}$ overnight, rinsed again and permeabilised with $0.2 \%$ Triton X-100 in PBS at room temperature for $30 \mathrm{~min}$. After another rinse step with PBS, cells were stained with a PI solution, as above, at room temperature under light protection for $15 \mathrm{~min}$. Visual inspection and fluorescent photography were carried out with a Zeiss (Jena, Germany) Axiovert 40 CFL inverted microscope and a Canon (Tokyo, Japan) PowerShot A620 digital camera.

\section{Quantification of scaffold-adhered cells}

To estimate numbers of layer-adhered viable cells after $5 \mathrm{~d}$ of in vitro pre-culture, the colorimetric XTT tetrazolium assay (Roche, Madrid, Spain) was carried out according to the manufacturer's instructions. Four control scaffold layers per round of surgery and cell type were transferred to 48-wells and incubated in XTT labelling solution under slow orbital shaking at $100 \mathrm{rpm}$ (Orbital shaking platform POS-300, Grant-bio, Grant Instruments, Cambridge, UK) and $37{ }^{\circ} \mathrm{C}$ in the $\mathrm{CO}_{2}$ incubator. Identical numbers of cells as seeded onto the scaffold layers were used as seeding number reference and analysed after $2 \mathrm{~h}$ of adherence on culture plastic in the $\mathrm{CO}_{2}$ incubator. Aliquots of the formazan dye product, resulting from tetrazolium metabolisation through mitochondrial dehydrogenases, were transferred to 96-wells, and absorbance was measured with a Synergy HT plate reader (BioTek, Winooski, VT, USA) at a wavelength of $492 \mathrm{~nm} /$ reference $690 \mathrm{~nm}$.

\section{Animal surgery}

All the experiments were carried out in conformity with the European Directive 2010/63/EU and the Spanish RD1201/2005 on care and use of animals in experimental procedures. Furthermore, the animal experiments were previously approved by the local committee of the University of La Laguna. The osteochondral defect was performed on 42 mature (6 month old) male New Zealand rabbits (3-4 kg), anaesthetised intramuscularly with ketamine $(35 \mathrm{mg} / \mathrm{kg})$ and xylazine $(5 \mathrm{mg} / \mathrm{kg})$. A dose of prophylactic antibiotic (enrofloxacin, Alsir ${ }^{\circledR}$, Esteve Veterinaria, Barcelona, Spain), subcutaneously (s.c.), $5-15 \mathrm{mg} / \mathrm{kg}$, and one of the analgesic buprenorphine (Buprex $^{\circledR}$, Schering Plough, Madrid, Spain), 0.05-0.1 mg/ $\mathrm{kg}$, s.c., were administered $30 \mathrm{~min}$ before intervention. Surgery was carried out in aseptic conditions as previously described (Reyes et al., 2012). The left hind legs were shaved and disinfected and a vertical medial parapatellar incision was made in the knee and the patella dislocated to allow access to the femoral condyles. A $4.5 \mathrm{~mm}$ diameter and $4 \mathrm{~mm}$ depth hole was created with a dental burr in the proximal area of the intercondylar space. One bilayered scaffold was inserted into the defect and the third layer (with or without cells) placed on top. Then, the patella and the patellar tendon were reduced and the surgical wound closed with stitches. After recovery from the surgery (20$30 \mathrm{~min}$ ), the animals were allowed free movement in their cages as well as food and water uptake. A single dose of the anti-inflammatory analgesic ketoprofen $(2-5 \mathrm{mg} / \mathrm{kg}$, s.c.) was administered to guarantee an overnight effect and thereafter buprenorphine every $12 \mathrm{~h}$ for $72 \mathrm{~h}$.

\section{Histological evaluation and scoring}

One scaffold per animal was implanted, and one animal from the same litter was the donor for the animals that received cell-loaded implants. Seven experimental groups of 6 animals each were considered for histological evaluation:

- Group C: control (empty defect)

- Group B: blank (cell- and GF-free scaffolds)

- Group BMP-2: scaffolds containing $5 \mu \mathrm{g}$ of BMP-2

- Group MSC: scaffolds precultured with rbMSCs

- Group rbC: scaffolds precultured with rbCs

- Group BMP-MSC: $5 \mu \mathrm{g}$ of BMP-2 in rbMSC precultured scaffolds

- Group BMP-rbC: $5 \mu \mathrm{g}$ of BMP-2 in rbC precultured scaffolds.

The defect bearing femora from 3 animals per experimental group and time point ( 6 and 12 weeks) were prepared for histological evaluation. Samples were fixed in $10 \%$ formalin solution ( $\mathrm{pH} 7.4$ ), decalcified in $10 \%$ formic acid solution, dehydrated in a graded series of ethanol, and embedded in Paraplast ${ }^{\circledR}$ (Biosigma, Tenerife, Spain). Longitudinal microtome (Shandon Finesse 325) sections of 3-5 $\mu \mathrm{m}$ of thickness were prepared throughout the defect site of each specimen. Then, they were stained with haematoxylin-erythrosine and toluidine blue to 


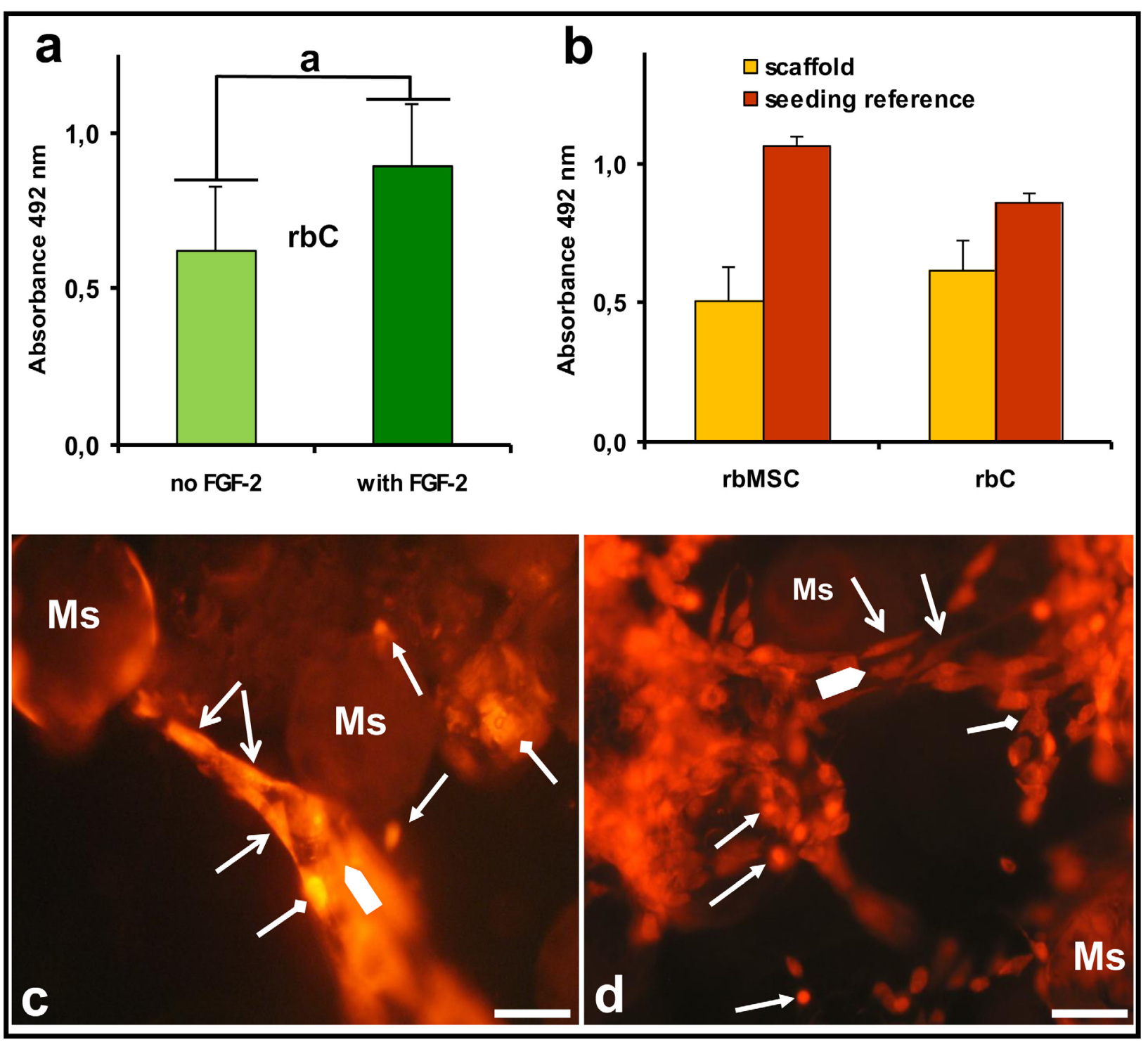

Fig. 2. In vitro cultured cells on alginate/PLGA microsphere layers for in vivo implantation. (a) Metabolic activity of viable rbCs on native scaffolds layers in absence versus presence of FGF-2 $(10 \mathrm{ng} / \mathrm{mL})$ after 5 days of culture. XTT tetrazolium assay (absorbance $492 \mathrm{~nm}$ ). ${ }^{a} p<0.05 . n=5$. (b) Metabolic activity of layer-seeded cells at the time of implantation ( $5 \mathrm{~d}$ after seeding) and their seeding reference $2 \mathrm{~h}$ after adhesion to culture plastic. XTT tetrazolium assay. $n=8$. (c) Fluorescence-photomicrograph of permeabilised, propidium iodide-stained rbMSCs on FBS-pretreated scaffold layers after $5 \mathrm{~d}$ of in vitro culture (the moment of implantation). Cells adhered to alginate fibre strings (compact arrow) and microspheres (Ms) with long extensions (open arrowhead), compact, spread phenotypes (rhomboid arrowhead), and round shapes with condensed chromatin (closed arrowhead). Scale bar $=20 \mu \mathrm{m}$. (d) Fluorescence-photomicrograph of permeabilised, propidium iodide-stained rbCs on native scaffold layers after $5 \mathrm{~d}$ of in vitro culture (the moment of implantation) in medium supplemented with $10 \mathrm{ng} / \mathrm{mL}$ of FGF-2. Fibroblast-like chondrocytes with long extensions (open arrowhead), particularly adhered to alginate fibre strings (compact arrow); round cells with condensed chromatin (closed arrowhead), and compact spread cells (rhomboid arrowhead) adhered to all scaffold structures, e.g., to microspheres (Ms). Scale bar $=30 \mu \mathrm{m}$.

identify osteochondral repair and finally inspected by light microscopy (LEICA DM 4000B, Leica Microsystems, Wetzlar, Germany). The histological findings were scored by two independent evaluators, using an established scoring system of six parameters for osteochondral repair, as described by Wakitani et al., (1994) and modified by Tokuhara et al. (2010). The evaluated parameters were cell morphology, with scores between 0 and 4, matrix staining (scores 0-3), surface regularity (scores 0-3), cartilage thickness (scores $0-2$ ), integration of donor to host adjacent cartilage (scores 0-2), and thickness of subchondral bone (scores $0-4$ ). Higher total scores were assumed as higher-quality cartilage and subchondral bone repair with a maximum score of 18 . Histological analysis of each of the above described parameters was performed by visual inspection by light microscopy (LEICA DM 4000B, Leica Microsystems) according to variations in structure and staining patterns compared to the adjacent normal cartilage. 


\section{Immunohistochemistry}

The following proteins were identified at the defect sites: collagen I (Col I) (Millipore, Barcelona, Spain, Catalogue No. AB749P) to characterise fibrous tissue and fibrocartilage, collagen II (Col II) (Millipore, Catalogue No. AB746P) for mature, functional, hyaline cartilage, collagen IX (Col IX) (Millipore, Catalogue No. 234194) as a marker for the cohesive and compressive properties of cartilage, collagen X (Col X) (Millipore, Catalogue No. 234196), typical for hypertrophic cartilage and endochondral ossification, and aggrecan (Millipore, Catalogue No. MAB2015), a cartilage-specific proteoglycan. For this purpose, sections were immunolabeled with anti-Col I, anti-Col II, anti-Col IX, and anti-Col X polyclonal antisera, and with an anti-aggrecan monoclonal antibody. The antisera against collagen I and collagen II recognise both the intracellular procollagen molecule and the extracellular collagen fibres, while the antiserum against collagen IX only recognises the intracellular procollagen molecule. Briefly, sections were deparaffinised and rehydrated in Tris-buffered saline (TBS) (pH 7.4, 0.1 M), which was also used for all further incubation and wash steps. The sections underwent antigen retrieval in Tris-EDTA buffer (pH 9.0, 10:1 mM) at $65{ }^{\circ} \mathrm{C}$ for $20 \mathrm{~min}$ and were then blocked in FBS at $2 \%$ in a TBS-Triton X-100 solution. The indirect immunohistochemical procedure was carried out by incubating the sections overnight at $4{ }^{\circ} \mathrm{C}$ with the mentioned antisera and antibody (1/100). After rinsing, sections were sequentially incubated with biotin-SP conjugated $\mathrm{F}(\mathrm{ab}$ ') fragment donkey anti-rabbit (Millipore) $(1 / 1000)$ and biotin-SP conjugated F (ab') fragment donkey anti-mouse (Millipore) (1/1000) for $60 \mathrm{~min}$ and streptavidin-peroxidase complex (Millipore) (1/1000) for another $60 \mathrm{~min}$. Peroxidase activity was revealed in Tris$\mathrm{HCl}$ buffer (pH 7.6, $0.05 \mathrm{M}$ ), containing $0.04 \%$ 4-chloro-1naphtol (Sigma, Poole, UK) and $0.01 \%$ hydrogen peroxide. Immunolabelling specificity was controlled by replacing the specific antiserum by normal serum.

\section{Quantitative analysis}

Col I, Col II, Col IX, Col X, and aggrecan immunoreactive cells per unit area $\left(1000 \mu \mathrm{m}^{2}\right)$ were counted using Leica Q-Win software (Analysis Image System Leica Q-Win, Barcelona, Spain). Ten sections throughout each defect were analysed in 3 animals per group and time point. Only cell profiles with immunostained cytoplasm and unstained nucleus were counted. Further, stained fragments and artefacts were excluded by the program itself, applying a threshold for minimum object size. In the case of aggrecan and Col II, where extracellular matrix and cells were immunolabelled, immunoreactive cells were identified manually and then quantified by the software. Intensity of immunolabelling, evaluated in arbitrary units of grey levels ranging from 0 (black) to 255 (white), was used as criterion for cell immunoreactivity assessment. Cells were considered reactive with values above the ones of their background control sections.

\section{Statistical analysis}

Statistical analysis was performed with SPSS V.18 software using one-way analysis of variance (ANOVA). Unpaired
Student's $t$-test was applied to analyse the effect of FGF2 on rbCs. Tukey's test was used for multiple post hoc comparisons. Significance was set at $p<0.05$. Results are given as means \pm standard deviation (SD).

\section{Results}

\section{MSCs and chondrocytes require distinct conditions} to expand on the same scaffold layers

First trials, to optimise scaffold cell loading and culture conditions, revealed that only few rbMSCs adhered to and proliferated on the untreated alginate/PLGA microsphere layers. Pre-incubation of the constructs in pure FBS gave better results (data not shown). On the contrary, proliferation of rbCs was extremely limited upon FBS pretreatment (containing bovine serum albumin (BSA), but also soluble collagens, fibronectin etc.), possibly analogous to chondrocyte behaviour in their natural matrix, but also poor on untreated scaffolds. Stimulation with FGF-2 significantly favoured $(p<0.05) \mathrm{rbC}$ expansion on the native scaffold surface (Fig. 2a). Thus, rbCs were finally cultured under FGF-2 supplementation on the original alginate/PLGA microsphere layers, while rbMSCs were seeded onto the FBS-treated layers and kept in complete medium without additional GF.

Seven control scaffold layers for either cell type were cultured together with the two times 6 implants assigned for in vivo application. At the time of implantation (after 5 days of culture), part of the controls were subjected to XTT analysis. The percentage of cells on the scaffold layers was approximately $50 \%$ and $70 \%$ for rbMSCs and $\mathrm{rbCs}$, respectively compared to initial seeding numbers (Fig. 2b). In addition, spontaneous PI uptake, which characterises dead cells, and subsequent PI staining of all fixed and permeabilised cells on the scaffolds was carried out. Only 1-2 dead cells per scaffold $(1 \pm 0.8)$ were detected by fluorescence microscopy by the end of the 5th day of in vitro culture (not shown).

Total rbMSC staining demonstrated spread cells, with (preferentially on alginate fibres) or without long extensions, as well as individual and groups of round cells with condensed chromatin (Fig. 2c) - a plausible sign of ongoing cell proliferation, taking into account the scarcity of dead cells. All types of cell shapes were observed in the rbC-loaded scaffold layers; but cells with long extensions tended to adhere to alginate fibre strings (Fig. 2d) and may indicate cell migration rather than dedifferentiation. The observed single, round cells in the scaffolds may stand for the differentiated chondrogenic phenotype; but the diverse aggregates of round cells may also have resulted from cell proliferation.

\section{Cell treated defects regenerate faster than the ones treated with BMP-2 solely or in combination Histological observations}

In vivo, the empty defects (group C) and the ones implanted with cell- and GF-free scaffolds (group B) did not differ from each other at the two time points of analysis ( 6 and 12 weeks). Histological analyses of specimens from both time points revealed no signs of repair in groups $\mathrm{C}$ and $\mathrm{B}$, where 
Normal Cartilage

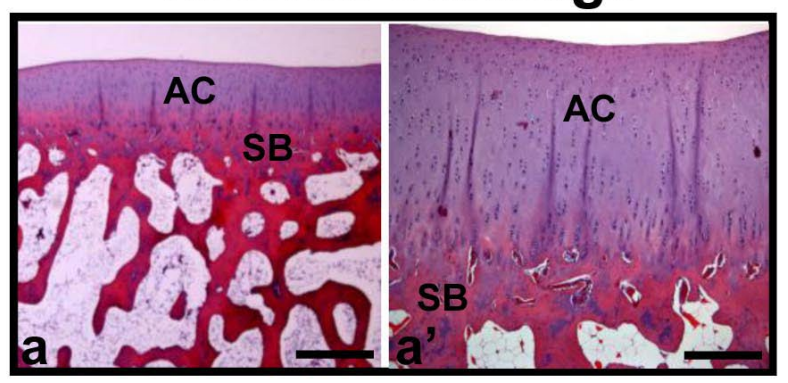

Blank (cell-GF-free scaffold)

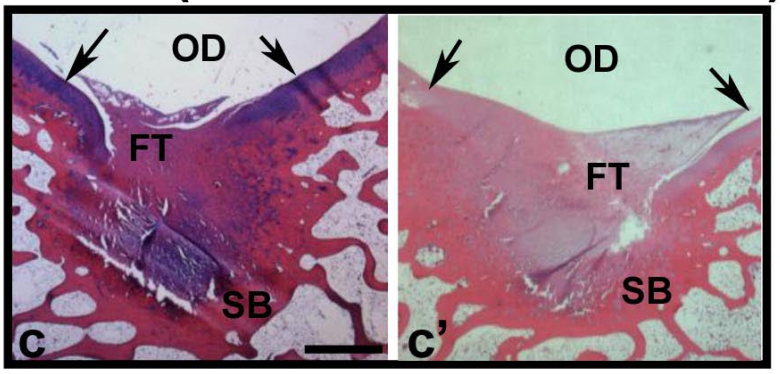

\section{MSC}

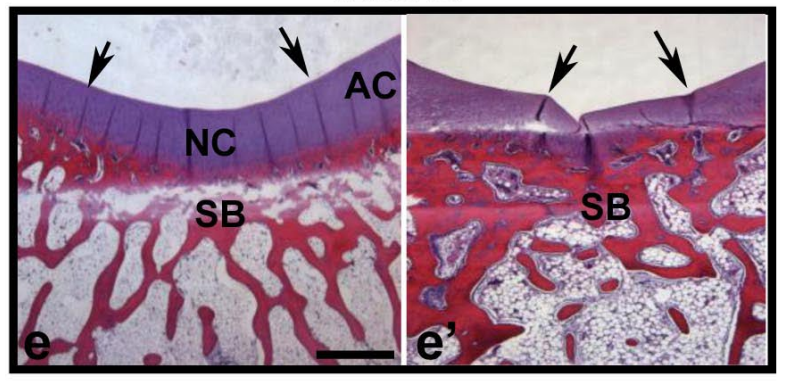

rbC

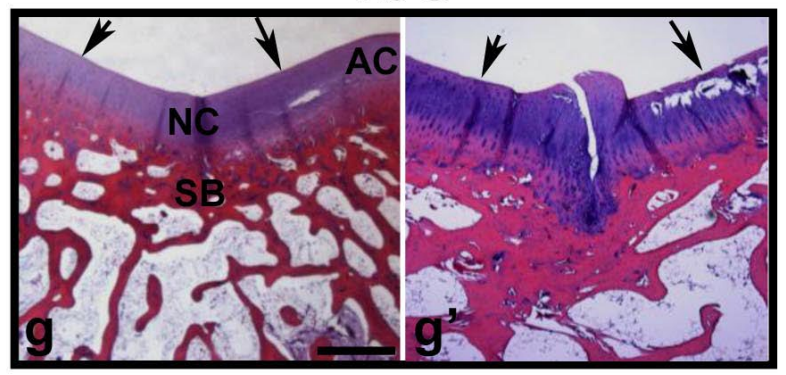

Control (empty defect)

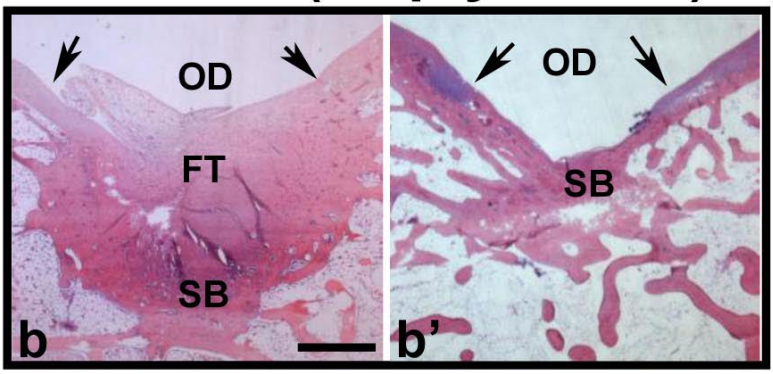

BMP-2

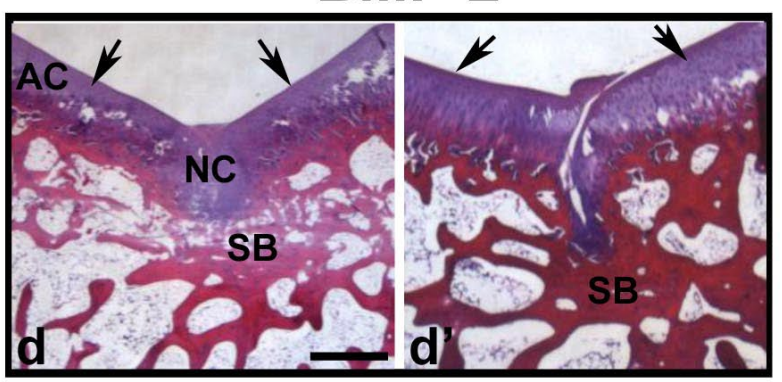

BMP-MSC

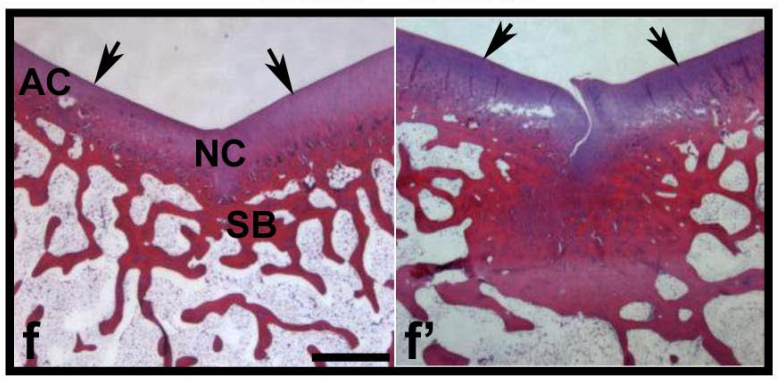

BMP-rbC

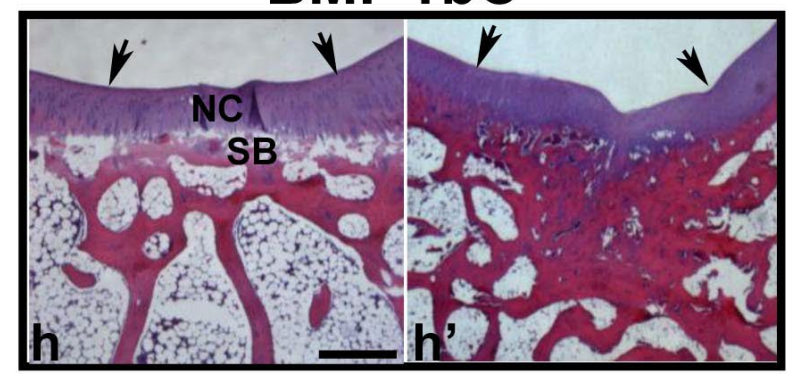

Fig. 3. Photomicrographs of osteochondral defect 6 weeks post-implantation. Representative images from horizontal sections of a rabbit femur, stained with haematoxylin-erythrosine, showing the osteochondral defect 6 weeks postimplantation in the best $(\mathbf{b}-\mathbf{h})$ and the worst ( $\mathbf{b}^{\prime}$-h') repaired specimen of the control group (empty defect; $\left.\mathbf{b}, \mathbf{b}^{\prime}\right)$, the blank group (scaffold alone; c, $\mathbf{c}^{\prime}$ ), and the treated groups BMP-2 (d,d'), MSC (e,e'), rbC (f,f'), BMP-MSC (g,g'), and BMP-rbC (h,h'). Figures a and a' show normal, articular cartilage at different magnifications. Arrows indicate defect extension. AC: adjacent cartilage; FT: fibrous tissue; NC: neocartilage; OD: osteochondral defect; SB: subchondral bone. Scale bars $\mathbf{a}, \mathbf{b}, \mathbf{b}^{\prime}-\mathbf{h}, \mathbf{h}^{\prime}=1.3 \mathrm{~mm}, \mathbf{a}^{\prime}=400 \mu \mathrm{m}$.

the defects appeared filled with a plug of fibrous tissue at 6 weeks (Fig. 3b,b' and Fig. 3c,c') and with a mixture of fibrous tissue and fibrocartilage 12 weeks (Fig. 4a,a' and Fig. 4b,b') post-implantation. No cartilage-like tissue had formed in both groups. Most specimens exhibited discontinuity between one or both defect borders and the normal adjacent cartilage (Fig. 3b,b', Fig. 3c,c', Fig. 4a,a', Fig. 4b,b'). A large area with proliferating bone cells filled the subchondral region beneath the fibrous tissue (Fig. 3b,b', Fig. 3c,c', Fig. 4b,b', Fig. 4c,c'). Figs. 3 and 
Normal Cartilage

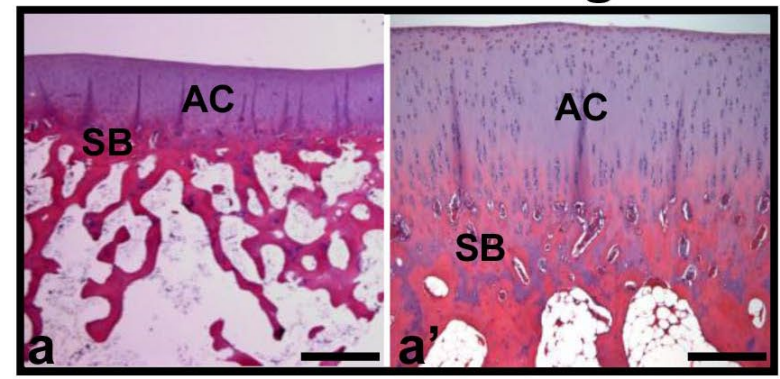

Blank (cell-GF-free scaffold)

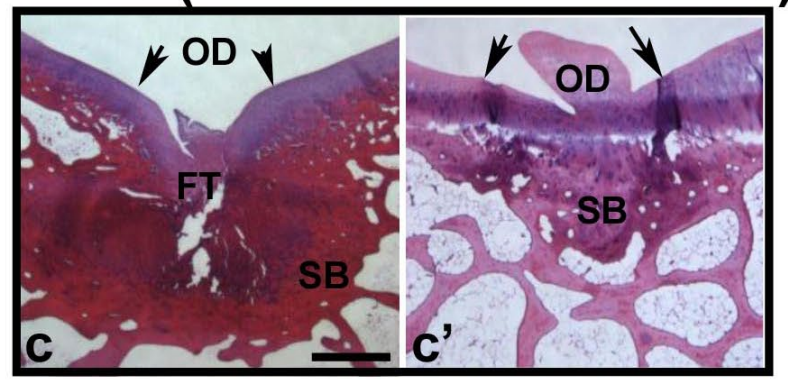

MSC

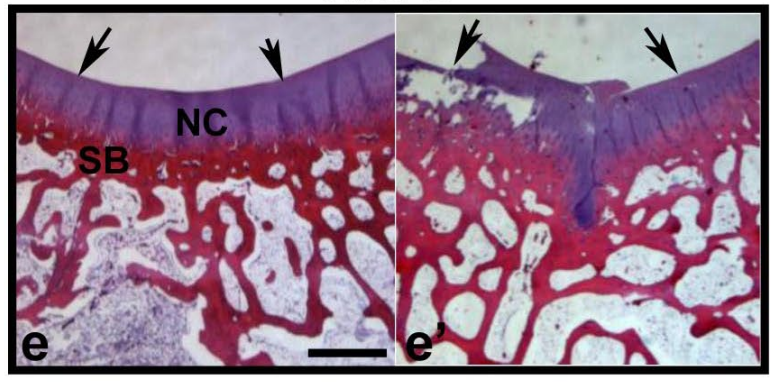

$\mathrm{rbC}$

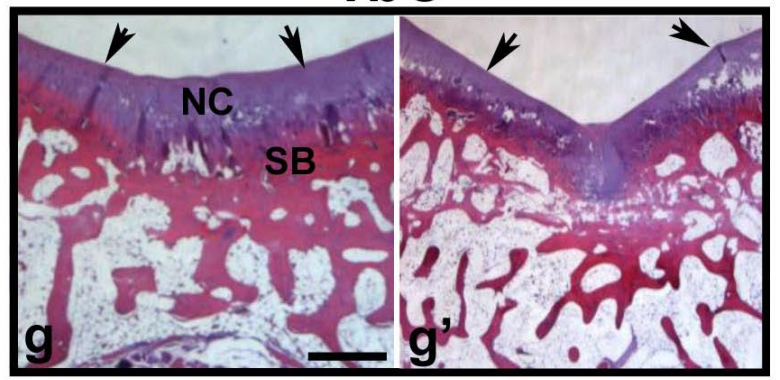

Control (empty defect)

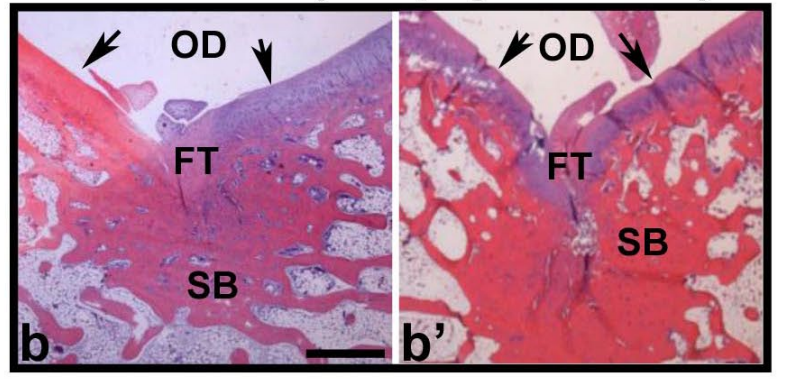

BMP-2

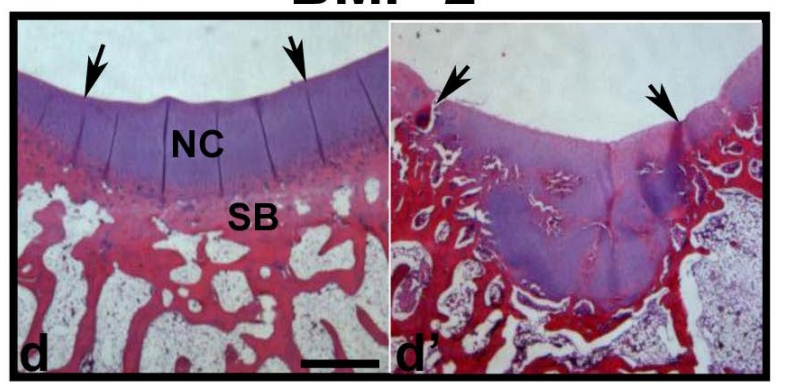

BMP-MSC

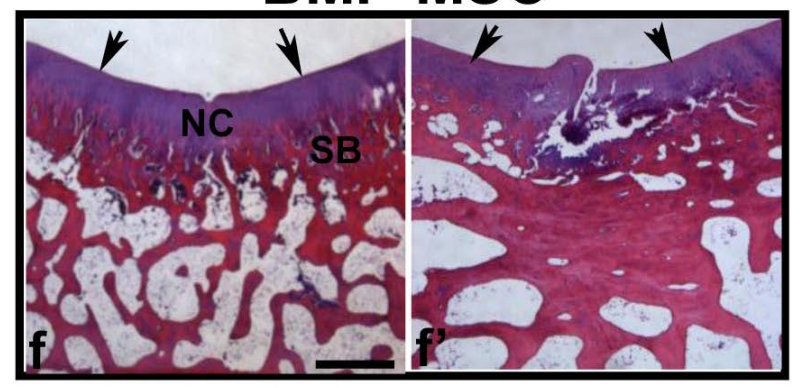

BMP-rbC

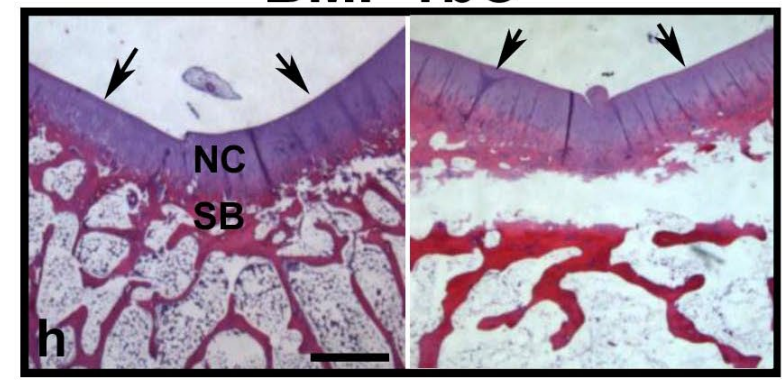

Fig. 4. Photomicrographs of osteochondral defect 12 weeks post-implantation. Representative images from horizontal sections of rabbit femurs, stained with haematoxylin-erythrosine, showing the osteochondral defect 12 weeks postimplantation in the best (b-h) and the worst (b'-h') repaired specimen of the control group (empty defect; $\left.\mathbf{b}, \mathbf{b}^{\prime}\right)$, the blank group (scaffold alone; c, $\left.\mathbf{c}^{\prime}\right)$, and the treated groups BMP-2 (d,d'), MSC (e,e'), rbC (f,f'), BMP-MSC (g,g'), and BMP-rbC (h,h'). Figures a and a' show normal, articular cartilage at different magnifications. Arrows indicate osteochondral defect extension. AC: adjacent cartilage; FT: fibrous tissue; FC: fibrocartilage; NC: neocartilage; OD: osteochondral defect; SB: subchondral bone. Scale bars $\mathbf{a}, \mathbf{b}, \mathbf{b}^{\prime}-\mathbf{h}, \mathbf{h}^{\prime}=1.3 \mathrm{~mm}, \mathbf{a}{ }^{\prime}=400 \mu \mathrm{m}$.

4 include images which allow comparison of the repair tissue with normal cartilage and the subchondral bone (Fig. 3a,a' and Fig. 4a,a').

Defect specimens from BMP-2 loaded implants differed remarkably from those of groups C and B 6 weeks postimplantation. The GF treated defects were characterised by partial cartilage repair with histological features similar to those of hyaline cartilage, although proliferation of anomalous cartilage with an irregular surface was apparent in the subchondral bone of most specimens (Fig. 3d,d').

Defect repair in specimens from cell-loaded implants and combinations of either cell type with BMP-2 (groups 

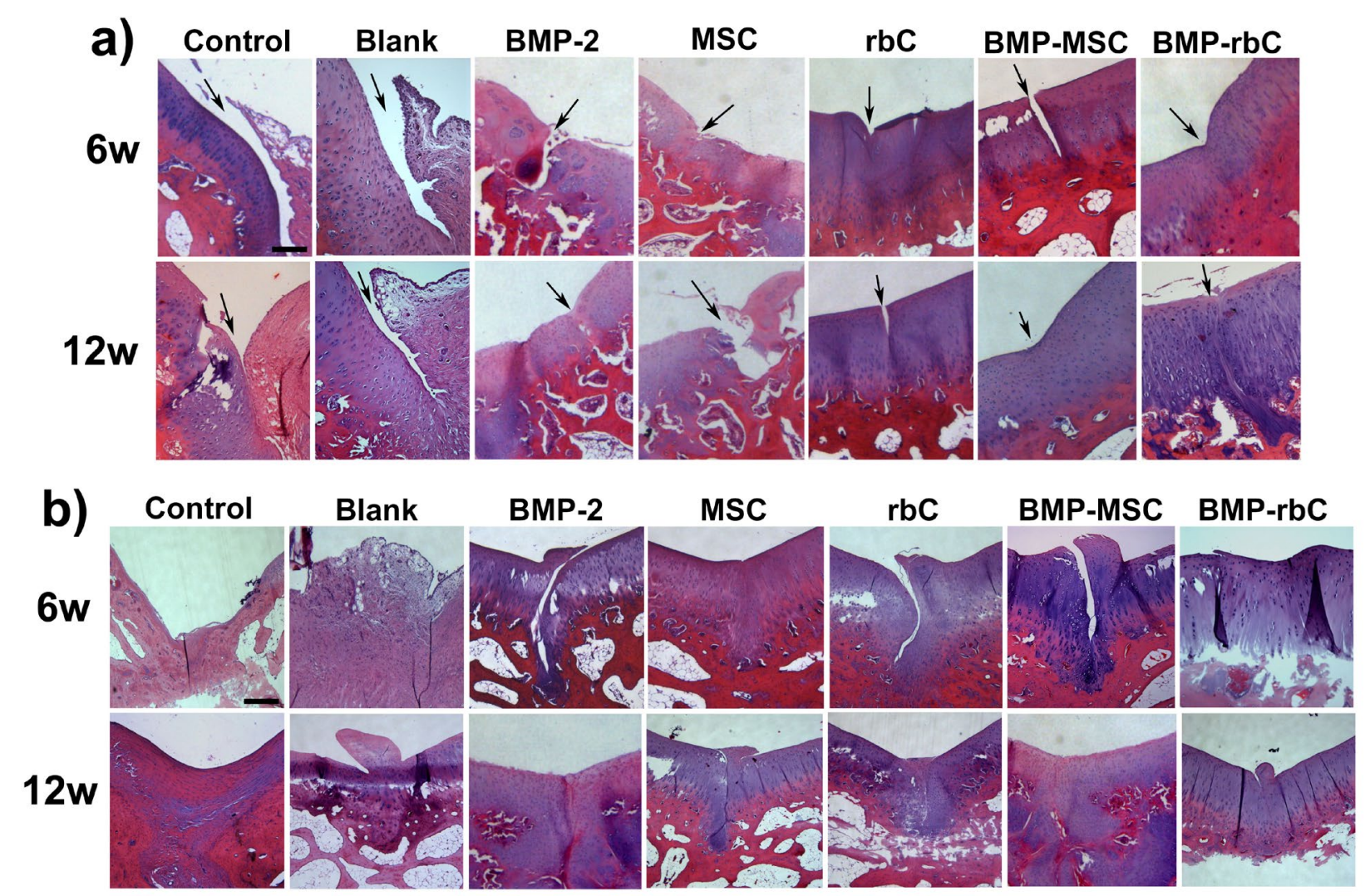

Fig. 5. Photomicrographs of osteochondral defect details 6 and 12 weeks post-implantation. Images of osteochondral defects in animals from all experimental groups, showing (a) a detail of the defect limit (arrow) and (b) the surface in the central defect area. Scale bars $=500 \mu \mathrm{m}$.

MSC/BMP-2 and rbC/BMP-2) differed remarkably from those of groups $\mathrm{C}$ and $\mathrm{B}$ but also from the group BMP26 weeks post-implantation. Cartilage-like tissue with similar characteristics as the adjacent, normal cartilage had formed in all four groups (MSC, rbC, MSC/BMP-2, and $\mathrm{rbC} / \mathrm{BMP}-2)$. All groups exhibited a high degree of repair. In some specimens, the defect borders were no longer identifiable, while the repair was not that perfect in others (Fig. 3e,e'-3h,h'). Likewise, the articular surface of the repair cartilage exhibited only little irregularity in some animals, while irregularities and clefts were more evident in others (Fig. 3d,d'-3g,g'). Cartilage thickness was almost identical to the adjacent, normal cartilage. Subchondral bone repair was complete (Fig. 3d,d'-3h,h'). No scaffold remnants were detected in any of the animals 6 weeks post-implantation. Furthermore, there were no signs of an inflammatory reaction at the defect site at this time.

After 12 weeks, repair in the group BMP-2 was complete and had increased with respect to 6 weeks (Fig. $4 \mathrm{~d}, \mathrm{~d}$ '). The defects of the cell treated groups (MSC, rbC, MSC/BMP-2, and rbC/BMP-2) resembled histologically the ones from 6 weeks post-implantation (Fig. 4e,e'-4h,h'). There were no marked differences between them.

Fig. 5 shows, in all experimental groups, details of the site of integration with the adjacent cartilage 6 and 12 weeks post-implantation (Fig 5a) and of the surface of the repair tissue 6 and 12 weeks post-implantation (Fig 5b).

\section{Histological scoring}

Scores from the histological findings revealed that there was no apparent osteochondral defect repair in groups $\mathrm{C}$ and $\mathrm{B}$, both after 6 and 12 weeks with scores between 2.3 and 5 (Fig. 6a-g).

By the end of the 6th week, the defects of BMP-2 treated animals differed significantly $(p<0.01)$ from those of groups $\mathrm{C}$ and $\mathrm{B}$ with scores around 10.33. Also, the groups MSC, rbC, MSC/BMP-2, and rbC/BMP-2 exhibited significant differences $(p<0.001)$ from groups $\mathrm{C}$ and $\mathrm{B}$ with scores between 13.67 and 16.33. Only the group MSC differed significantly $(p<0.05)$ from the group BMP-2 (Fig. 6a-g).

Histological scoring of 12 weeks' samples resulted in values of 15.33-16.67 in all treated groups with significant differences $(p<0.001)$ to groups $\mathrm{C}$ and $\mathrm{B}$. Treated groups did not differ significantly from each other at this time point (Fig. 6a-g).

Analyses of cell morphology and matrix staining (Fig. $6 b, c)$ were complemented by assessment of the different cell types within the osteochondral defects. Cell counts revealed significant differences in Col I immunoreactive cells (fibroblastic cells) between groups $\mathrm{C}$ and $\mathrm{B}$, on the one hand, and the treated groups, on the other hand, both 6 and 12 weeks post-implantation (Fig. 7a,f). These differences were even highly significant for the chondrogenic markers Col II and aggrecan, again after 6 and 12 weeks (Fig. 

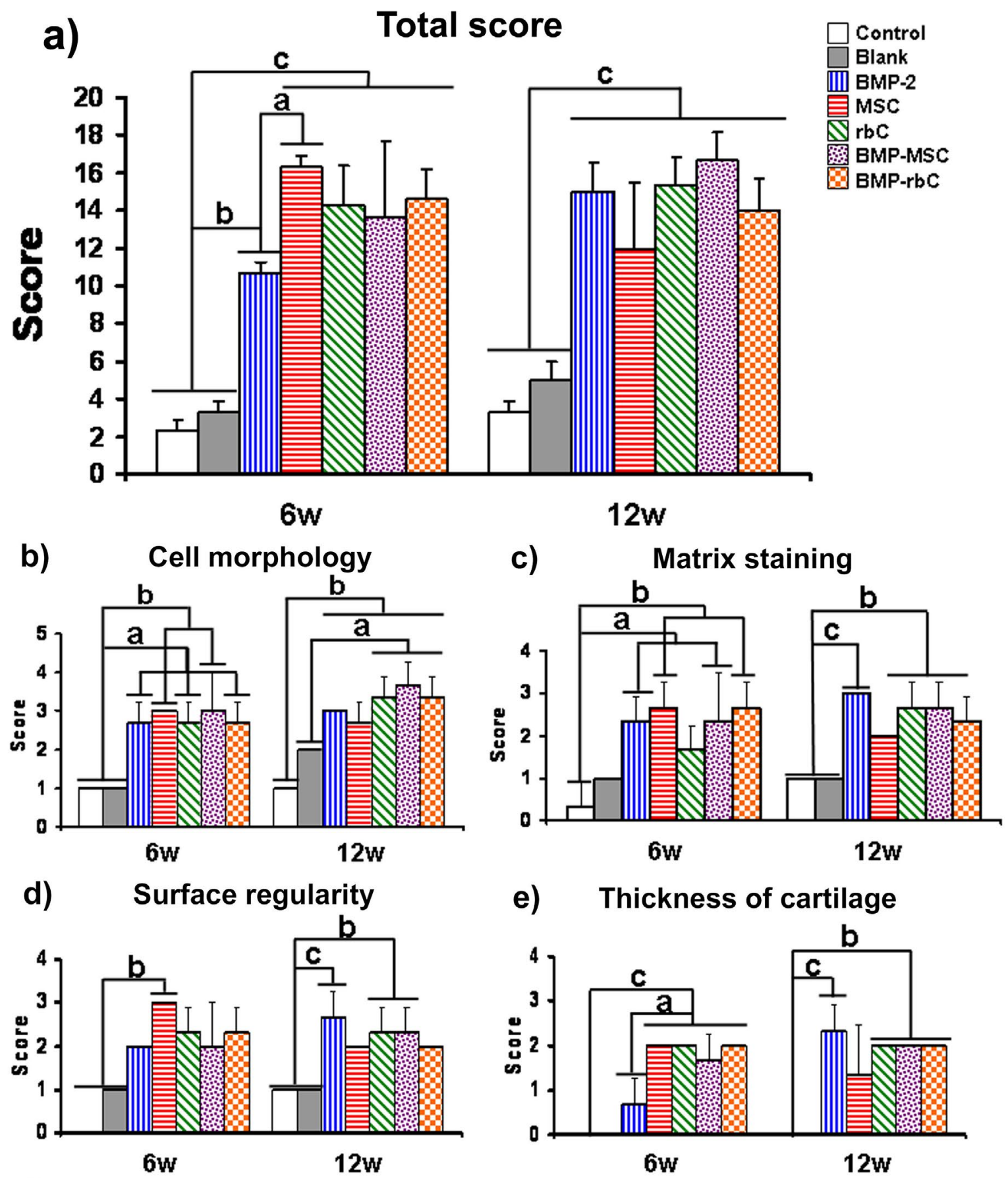

e) Thickness of cartilage

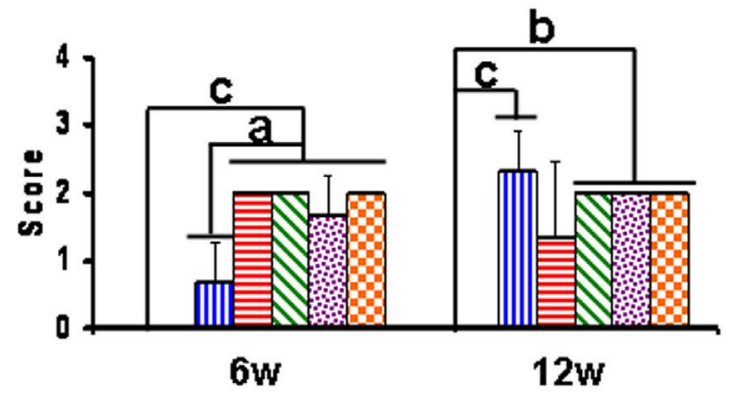

f) Integration of donor to host adjacent cartilage
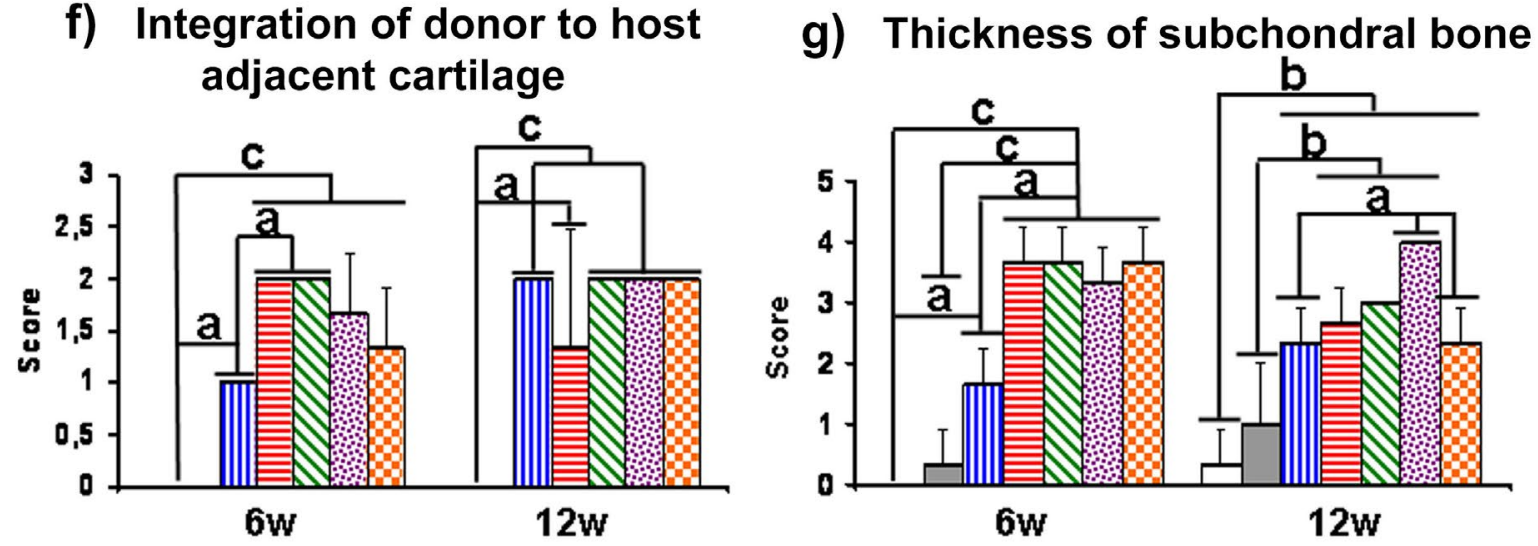

Fig. 6. Histological scoring. Overall histological scores for the osteochondral repair process (a). Histological scores of cell morphology (b), matrix staining (c), surface regularity (d), thickness of cartilage (e), integration of donor to host adjacent cartilage (f), and thickness of subchondral bone (g) in the different experimental groups; ${ }^{a} p<0.05,{ }^{b} p<0.01$, and ${ }^{c} p<0.001 . n=3$. 
a)

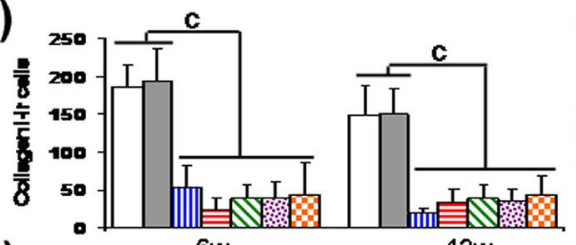

b)
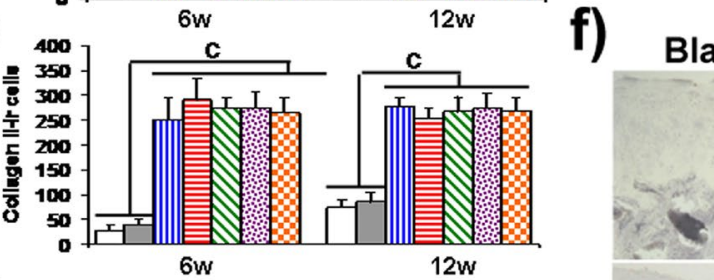

c)

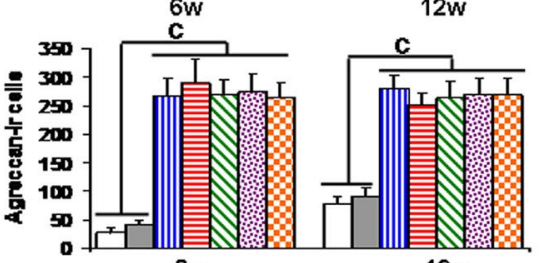

d)
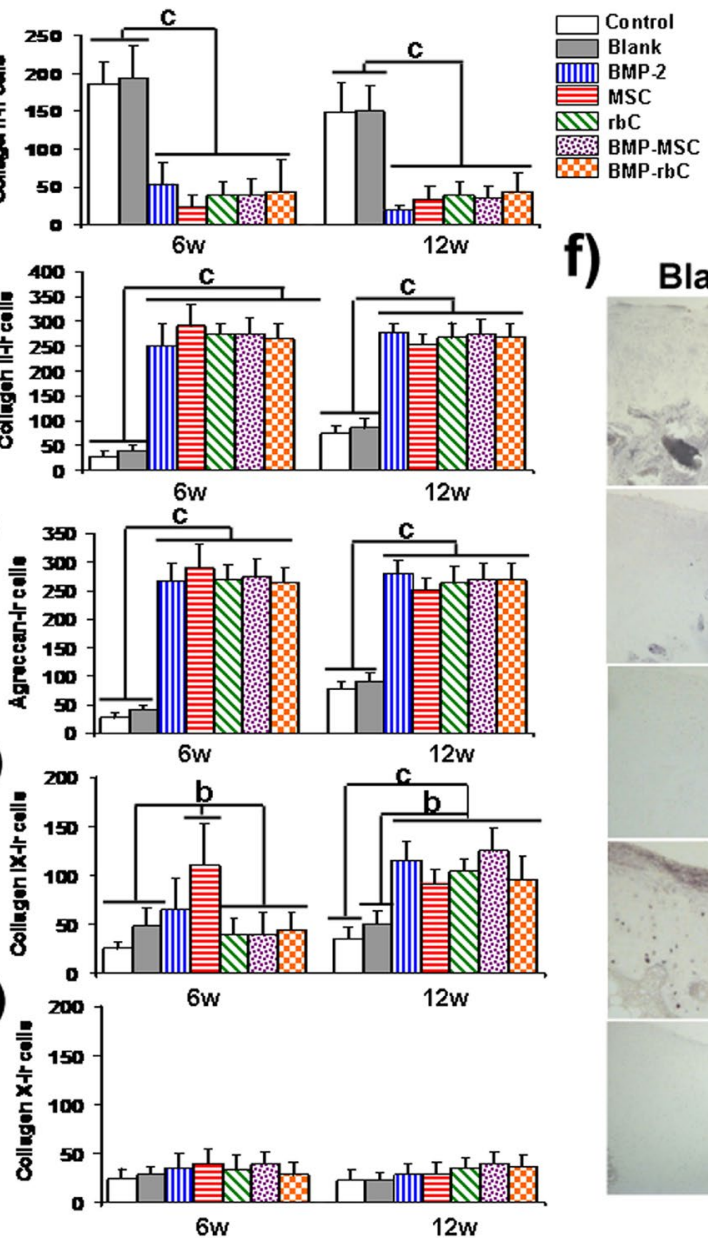

f)

Blank 12w

BMP-2 12w BMP-MSC 12w

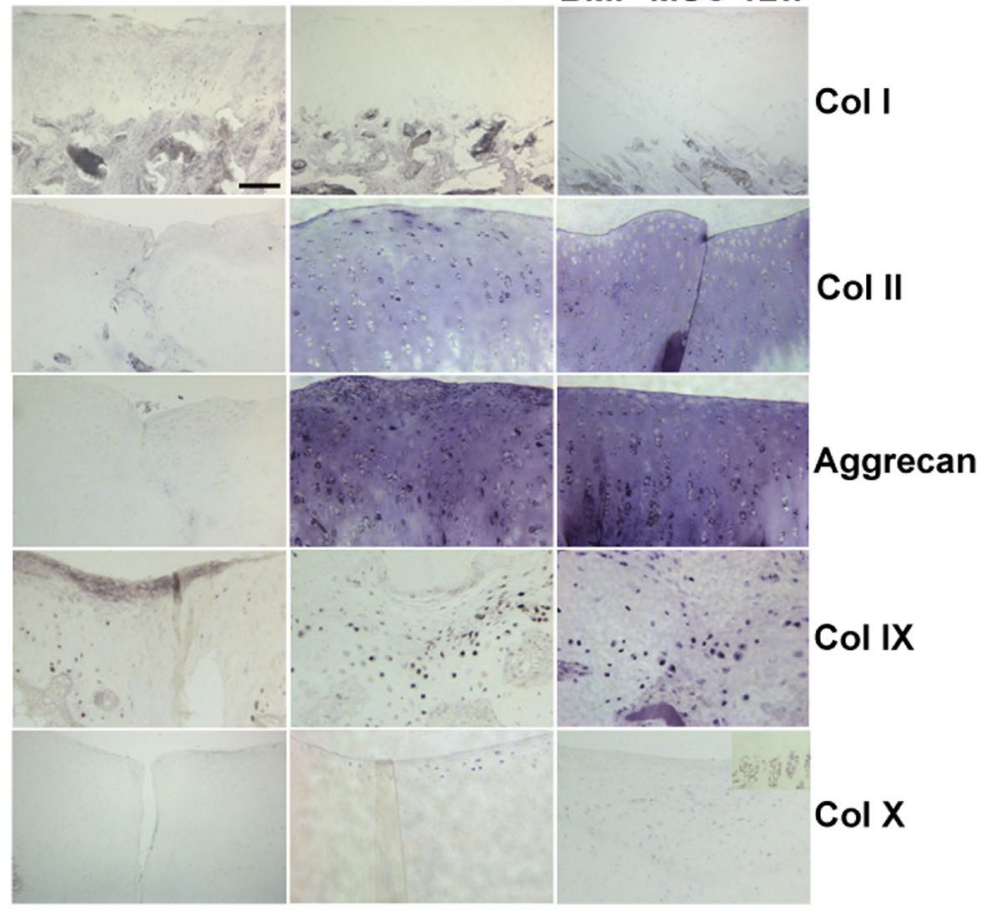

Fig. 7. Cell markers. Numbers of immunoreactive cells for Col I (a), Col II (b), aggrecan (c), Col IX (d), and Col X (e) in the different experimental groups $6(6 \mathrm{w})$ and $12(12 \mathrm{w})$ weeks post-implantation. Histograms represent means of immunolabelled cells per unit area $\left(1000 \mu \mathrm{m}^{2}\right) \pm \mathrm{SD}$ at different time points; ${ }^{b} p<0.01$ and ${ }^{c} p<0.001$. $n=3$. (f) Representative images from the groups blank, BMP-2, and BMP-MSC showing immunolabelling for the different markers inside the osteochondral defect 12 weeks post-implantation. The inset in the last image represents a positive control for collagen X demonstrating immunoreactivity in the growing cartilage during endochondral ossification. Scale bar $=50 \mu \mathrm{m}$.

7b,c,f). Numbers of Col IX immunoreactive cells revealed significant differences between cell and GF treated defects and groups $\mathrm{C}$ and $\mathrm{B}, 12$ weeks post-implantation (Fig. $7 \mathrm{~d}, \mathrm{f}$ ), while, after 6 weeks, only the group implanted with rbMSCs proved to be significantly different from the other groups, except for the group BMP-2 (Fig. 7d). Very low numbers of Col X immunoreactive cells were detected in all groups along the experimental period with no significant differences between them (Fig. 7e,f).

\section{Discussion}

Management of cartilage defects is still not ideally resolved. With evolving techniques and technologies, application of cells may further improve current treatment modalities. Thus, a cell-based tissue engineering approach to advanced cartilage repair strategies may substantially benefit public health on the clinical as well as the economic level. MSCs are currently investigated as an alternative to chondrocytes for cartilage defect repair. However, cartilage tissue engineering systems with either cell type have been shown to be successful in some cases and to different extents in various animal models (Grässel and Anders, 2012). Although large animal models (such as pigs, goats, and horses) may more closely resemble the human system, the herein used rabbit model is one of the well accepted small animal models for evaluation of GF or cell-loaded scaffolds in cartilage defects (Sellers et al., 1997; Sellers et al., 2000; Rudert, 2002; 2005; Shao et al., 2006; Holland et al., 2007; Qi et al., 2009; Im and Lee, 2010; Jiang et al., 2010; Tokuhara et al., 2010; Wang et al., 2010; Chen et al., 2011; Qi et al., 2011; Yang et al., 2011; Qi et al., 2012; Zhang et al., 2013). Additional to the choice of an adequate animal model, there are still a number of challenges to be overcome in the search for optimum cartilage repair conditions as e.g., the recognition of the optimal cell source, scaffolds, and GFs.

One of the potential problems in clinical cell implantation for cartilage repair is the limited number of 
available autologous cells. Particularly cartilage biopsies, but also bone marrow aspirates, provide only few cells. On the other hand, cell expansion for clinical application should ideally be short and not modify the phenotype. One of the aims of this study was to verify whether alginate/ PLGA implants with small numbers of either rbMSCs or rbCs in a low passage could improve cartilage repair. To this end, growth conditions on the scaffolds were optimised in vitro for either cell type.

The number of rbMSCs per scaffold clearly augmented when the material was pre-treated with serum-derived matrix proteins compared to the native material. Therefore, we applied this pre-treatment for the rbMSC-assigned implants.

Chondrocytes from hyaline cartilage gradually change to a fibroblast-like phenotype and increase their proliferative potential during serial expansion in monolayers. Despite partial redifferentiation when exposed to an environment that prevents cell flattening, chondrocytes never fully recover their chondrogenic phenotype (Martin et al., 1999). In this study, chondrocytes were seeded onto the scaffolds after only 2 passages of two-dimensional expansion. Interestingly, cell numbers did not increase, even within 5 days on the FBS-treated material (containing BSA, but also soluble collagens, fibronectin etc.), possibly resembling chondrocyte behaviour in natural extracellular matrix, i.e., in cartilage. Nonetheless, chondrocyte seeding on untreated scaffolds resulted in a moderate increase in proliferation and was thus established as standard for this cell type. Martin et al. (1999) had demonstrated that chondrocytes fully maintain their potential for redifferentiation in response to a three-dimensional environment after longterm expansion on culture plastic in the presence of FGF2. Based on this data, we decided to treat the rbCs on the three-dimensional layer with FGF-2. The objective was to induce cell proliferation in three-dimensional conditions before implantation into a cartilage environment, but also to stimulate continuing cell migration for some period after implantation. Cell phenotypes observed after 5 days of in vitro supplementation with FGF-2 corroborated the presence of migrating and proliferating cells on the distinct structures (PLGA microspheres and alginate fibres) of the scaffold layer.

The addition of FGF-2 has been reported also to enhance marrow derived MSC proliferation and favour their chondrogenic potential. However, this process is accompanied by up-regulation of COL10A1 - the gene encoding the alpha chain of type X collagen - expressed during hypertrophic differentiation, together with COL2A1 in the presence of BMP-2. This effect was absent in human articular chondrocytes subjected to monolayer or three-dimensional culture (Freyria and Mallein-Gerin, 2012). Thus, the probably different regulatory controls for these two genes in MSCs and chondrocytes led us not to stimulate rbMSCs with FGF-2 in vitro.

The limited number of autologous chondrocytes from the spare cartilage donor sites may hardly meet the high demand of cells to engineer cartilage in vitro. Some authors report low cell-seeding densities on biomaterials of e.g. $10-130 \times 10^{6}$ cells $/ \mathrm{cm}^{3}$ to develop cartilage with acceptable mechanical properties (Chiang and Jiang, 2009). However, to achieve even these densities, the harvested chondrocytes must be expanded in vitro before seeding.

In the present study, we evaluated cell therapies with rbCs and rbMSCs, on the one hand, and their combination with BMP-2, on the other hand, for the repair of a fullthickness cartilage defect. The results demonstrate a higher efficacy of both cell therapy approaches, compared to treatment with BMP-2 alone, 6 weeks post-implantation, although the difference to the sole BMP-2 treatment was only significant for rbMSCs. However, 12 weeks postimplantation, all treatment modalities resulted in similar outcomes, and most importantly, we observed no additive effect in combinations of cells with BMP-2 at any time point. Histological analyses of the samples treated with either cell type revealed cartilage-like tissue 6 weeks postimplantation, which conserved its structure at least through the 12 weeks. However, there was a decrease in the score of the MSC group, which failed to be statistically significant. We assume this decrease not to be representative, as 2 of the 3 animals in this group had a total score of 14, but the third did not respond well to the treatment, probably due to an individual physiological variability. A larger number of animals per group may have dispelled the doubts. However, many published trials (for example, Yan and Yu, 2007; Dashtdar et al., 2011) demonstrate that a minimum of 3 animals per group is not only easier to justify ethically than larger groups but also completely valid and exhibits a statistically acceptable degree of variability.

On the whole, this study revealed no advantage of one cell type over the other, neither in the scores of the different histological parameters nor other aspects not assessable to a scoring system, such as cell rearrangement. We observed satisfactory outcomes, i.e., formation of cartilage-like tissue, 6 weeks post-implantation and similarly 12 weeks post-implantation.

Contrastingly, Guo et al. (2010) had not observed any effect on osteochondral defect repair in rabbits, when using MSCs solely or in combination with chondrogenesis-inducing GFs, such as TGF- $\beta 1,12$ weeks post-implantation. In agreement with our observations, Dashtdar et al. (2011) observed a good and equivalent degree of repair and hyaline cartilage formation with MSCs and chondrocytes, differentiated from MSCs, 12 weeks post-implantation with continuing stability 24 weeks post-implantation. Li et al. (2009) compared xenogeneic MSCs and allogeneic chondrocytes in a full-thickness, but not osteochondral, cartilage defect in a swine model. Their MSC-seeded constructs elicited almost complete repair, while chondrocytes produced mostly fibrocartilage-like tissue. As a connection to the bone marrow cavity was avoided, the lack of contact to the resident MSCs and other components could be speculated to be the origin for the contrasting results.

First approaches in cartilage tissue engineering with MSCs consisted of micromass cultures in the presence of TGF- $\beta$ (Yang et al., 2006). Though TGF- $\beta 1$ positively regulates the expression of several cartilage proteins, the presence of TGF- $\beta 1$ in vitro has been related to hypertrophic differentiation of chondrocytes (Narcisi et al., 2012). Longterm exposure to BMP-2 through gene transfer, on the other hand, efficiently induces chondrogenic differentiation of 
human MSCs with no sign of hypertrophic maturation or osteogenic induction (Freyria and Mallein-Gerin, 2012). Other authors detected modest modulatory effects of BMP-2 on the expression of COL10A1 and osteocalcin in chondrocyte cultures but did not look at protein expression (Claus et al., 2010). Finally, a work by Jeong et al. (2012) suggests that BMP-2 does not promote cartilage hypertrophy and endochondral ossification to the same extent as it promotes cartilage formation. The latter group pre-treated primary chondrocytes on scaffolds with BMP2 for 6 weeks and analysed them after 5 more weeks of subcutaneous implantation. The authors speculate that continuous availability of BMP-2 may drive chondrocytes to more enhanced endochondral ossification after initial induction of cartilage matrix production. The herein presented data discard this hypothesis. Moreover, these authors and other groups propose that BMP-2 and TGF- $\beta 1$ may work synergistically and interactively together for chondrogenesis such that BMP-2 promotes chondrocyte differentiation, whereas TGF- $\beta 1$ modulates chondrocyte maturation and terminal differentiation led by BMP-2. We suggest that the cocktail of GFs and interleukins present in osteochondral defects participates to a decisive extent in the differentiation process of the implanted cells. A study by Chen et al. (2005) supports this hypothesis. The authors co-cultured adult MSCs with synovial fluid or cells or alternatively implanted them on a PLGA construct into the joint cavities of sheep. They detected chondrogenic markers in the co-culture systems after only 1 or 2 weeks and collagen II and sulphated proteoglycans, but no osteocalcin, on the implanted constructs after 4 and 8 weeks.

Herein, the repair cartilage, induced by implantation of either cell type as well as sustained release of BMP-2 solely, expressed the markers collagen II, aggrecan, and collagen IX, typical for chondrogenic differentiation, 12 weeks post-implantation. The expression of these molecules during the repair process of the osteochondral defect supports the histological findings; particularly, the expression of collagen type IX is essential for adequate cartilage formation and maturation as demonstrated with knock-out mice for this molecule (Opolka et al., 2007). Similarly, collagen type II and aggrecan indicate cartilagelike tissue. Moreover, recent studies support a correlation between increased degradation of both molecules, particularly collagen type II, with degenerative disorders of articular cartilage as in osteoarthritis (Dejica et al., 2008; Dejica et al., 2012). In addition, collagen $X$ and collagen I proteins were histologically undetectable, thus further pointing to the presence of cartilage-like tissue.

The total lack of an additive or synergistic effect of the combination of BMP-2 with either cell type indicates that both treatments are valid for cartilage defect repair. In this setup, cell therapy has shown greater effectiveness than BMP-2 therapy 6 weeks post-implantation, but the effect equalised toward 12 weeks.

Time course in human osteochondral defect treatment cannot be predicted. Though it seems to take longer to achieve a comparable degree of cartilage repair with BMP2 treatment, it is much less complicated and cheaper than preparing cells for implantation while meeting the complex legal requirements. Recombinant BMP-2 is FDA approved for bone treatment. Clinical outcomes in bone repair were not as good as expected, but a system for sustained release of BMP-2 may have given different results. Our group had previously demonstrated that the herein applied BMP-2 release system with a GF release period of 6 weeks led to the formation of cartilage-like tissue in rabbits that was maintained for at least 24 weeks (Reyes et al., 2012).

With the findings of this study in mind, either therapy - implantation of MSCs or chondrocytes and implantation of a system for sustained release of BMP-2 - will have to be evaluated by augmenting the number of experimental animals and perhaps also a scale-up of the animal model to evaluate the feasibility of this approach.

\section{Conclusions}

To the best of our knowledge, this is the only study that directly compares chondrocyte with MSC implantation, on the one hand, and sustained, local in vivo GF release, on the other hand, all mediated by identical scaffold systems in the same osteochondral-defect animal model. With time, all three modalities were equally efficient in successful osteochondral defect repair; but implantation of either cell type facilitated this degree of repair within half of the treatment period that was necessary under local, sustained release of BMP-2. Combinations of cells with BMP-2 did not further accelerate the process. These findings may be biased by the environment, created by the typical conditions within an osteochondral defect, i.e., the presence of blood and its components. Taking the latter into consideration, the present study represents a starting point for further work to come up with optimal conditions for osteochondral defect repair.

\section{Acknowledgements}

This work was supported by the Ministry of Science and Technology (MAT2008-02632 and MAT2011-23819) and Hospiten Holding S.L. (Convenio CI02320701). The authors are also grateful for Antonio Perera's technical assistance. The authors would like to thank members of the Department of Cell Biology of the University of La Laguna for receiving R. Reyes in their laboratory. We thank Dr. Carmen Damas for assistance with statistical analysis.

\section{References}

Bartlett W, Gooding CR, Carrington RW, Skinner JA, Briggs TW, Bentley G (2005) Autologous chondrocyte implantation at the knee using a bilayer collagen membrane with bone graft. A preliminary report. J Bone Joint Surg 87B: $330-332$.

Brittberg M, Lindahl A, Nilsson A, Ohlsson C, Isaksson O, Peterson L (1994) Treatment of deep cartilage defects in the knee with autologous chondrocyte transplantation. N Engl J Med 331: 889-895. 
Claus S, Aubert-Foucher E, Demoor M, Camuzeaux B, Paumier A, Piperno M, Damour O, Duterque-Coquillaud M, Galéra P, Mallein-Gerin F (2010) Chronic exposure of bone morphogenetic protein-2 favors chondrogenic expression in human articular chondrocytes amplified in monolayer cultures. J Cell Biochem 111:1642-1651.

Chen J, Wang CH, Lü S, Wu J, Guo X, Duan C. Dong L, Song Y, Zhang J, Jing D, Wu L, Ding J, Li D (2005) In vivo chondrogenesis of adult bone-marrow-derived autologous mesenchymal stem cells. Cell Tissue Res 319: 429-438.

Chen J, Chen H, Li P, Diao H, Zhu S, Dong L, Wang R, Guo T, Zhao J, Zhang J (2011) Simultaneous regeneration of articular cartilage and subchondral bone in vivo using MSCs induced by a spatially controlled gene delivery systems in bilayered integrated scaffolds. Biomaterials 32: 4793-4805.

Chiang H, Jiang CC (2009) Repair articular cartilage defects: Review and perspectives. J Formos Med Assoc 108: $87-101$.

Dashtdar H, Rothan H A, Tay T, Ahmad RE, Ali R, Tay LX, Chong PP, Kamarul TA (2011) Preliminary study comparing the use of allogenic chondrogenic predifferentiated and undifferentiated mesenchymal stem cells for the repair of full thickness articular cartilage defects in rabbits. J Orthop Res 29: 1336-1342.

Dejica VM, Mort JS, Laverty S, Percival MD, Antoniou J, Zukor DJ, Poole AR (2008) Cleavage of type II collagen by cathepsin $\mathrm{K}$ in human osteoarthritic cartilage. Am J Pathol 173: 161-169.

Dejica VM, Mort JS, Laverty S, Antoniou J, Zukor DJ, Tanzer M, Poole AR (2012) Increased type II collagen cleavage by cathepsin $\mathrm{K}$ and collagenase activities with aging and osteoarthritis in human articular cartilage. Arthritis Res Ther 14: R113.

Fortier La, Barker JU, Strauss EJ, McCarrel TM, Cole BJ (2011) The role of Growth factors in Cartilage Repair. Clin Orthop Relat Res 469: 2706-2715.

Freyria A-M, Mallein-Gerin F (2012) Chondrocytes or adult stem cells for cartilage repair: The indisputable role of growth factors. Injury 43: 259-265.

Gouttenoire J, Bougault C, Aubert-Foucher E, Perrier E, Ronzière M-C, Sandell L, Lundgren-Akerlund E, MalleinGerin F (2010) BMP-2 and TGF- $\beta 1$ differentially control expression of type II procollagen and $\alpha 10$ and $\alpha 11$ integrins in mouse chondrocytes. Eur J Cell Biol 89: 307-314.

Grässel S, Anders S (2012) Cell-based therapy options for osteochondral defects. Autologous mesenchymal stem cells compared to autologous chondrocytes. Der Orthopäde 5: 415-428.

Guo X, Park H, Young S, Kretlow JD, van den Beucken JJ, Bagget LS, Tabata Y, Kasper FK, Mikos AG, Jansen JA (2010) Repair of osteochondral defects with biodegradable hydrogel composites encapsulating marrow mesenchymal stem cells in a rabbit model. Acta Biomater 6: 39-47.

Harris JD, Siston RA, Pan X, Flanigan DC (2010) Autologous Chondrocyte Implantation. A Systematic Review. J Bone Joint Surg Am 92: 2220-2233.

Hellingman CA, Koevoet W, van Osch GJ (2012) Can one generate stable hyaline cartilage from adult mesenchymal stem cells? A developmental approach. J Tissue Eng Regen Med 6: e1-e11.

Hernández A, Sánchez E, Soriano I, Reyes R, Delgado A, Évora C (2011) Material-related effects of BMP-2 delivery systems on bone regeneration. Acta Biomater 8: 781-791.

Holland TA, Bodde EW, Baggett LS, Tabata Y, Mikos AG, Jansen JA (2005) Osteochondral repair in the rabbit model utilizing bilayered, degradable oligo(poly(ethylene glycol) fumarate) hydrogel scaffolds. J Biomed Mater Res A 75: 156-167.

Holland TA, Bodde EW, Cuijpers VM, Baggett LS, Tabata Y, Mikos AG, Jansen JA (2007) Degradable hydrogel scaffolds for in vivo delivery of single and dual growth factors in cartilage repair. Osteoarthritis Cartilage 15: 187-197.

Im GI, Lee JH (2010) Repair of osteochondral defects with adipose stem cells and a dual growth factor-releasing scaffold in rabbits. J Biomed Mater Res B Appl Biomater 92: $522-560$.

Ito S, Sato M, Yamato M, Mitani G, Kutsuna T, Nagai T, Ukai T, Kobayashi M, Kokubo M, Okano T, Mochida J (2012) Repair of articular cartilage defect with layered chondrocyte sheets and cultured synovial cells. Biomaterials 33: 5278-5286.

Jacobi M, Villa V, Magnussen RA, Neyret P (2011) MACI - a new era? Sports Med Arthrosc Rehabil Ther Technol 3:10.

Jeong CG, Zhang H, Hollister SJ (2012) Threedimensional polycaprolactone scaffold-conjugated bone morphogenetic protein- 2 promotes cartilage regeneration from primary chondrocytes in vitro and in vivo without accelerated endochondral ossification. J Biomed Mater Res Part A 100: 2088-2096.

Jiang Y, Chen LK, Zhu DC, Zhang JR, Guo C, Qi YY, Ouyang HW (2010) The inductive effect of bone morphogenetic protein-4 on chondral-lineage differentiation and in situ cartilage repair. Tissue Eng Part A 16: 1621-1632.

Kangwon Lee K, Silva EA, Mooney DJ (2011) Growth factor delivery-based tissue engineering: general approaches and a review of recent developments. J R Soc Interface 8: 153-170.

Khan W, Johnson DS, Hardingham TE (2010) The potential of stem cells in the treatment of knee cartilage defects. The Knee 17: 369-374.

Li W-J, Chiang H, Kuo T-F, Lee H-S, Jiang C-C, Tuan RS (2009) Evaluation of articular cartilage repair using biodegradable nanofibrous scaffolds in a swine model: a pilot study. J Tissue Eng Regen Med 3: 1-10.

Martin I, Vunjak-Novakovic G, Yang J, Langer R, Freed LE (1999) Mammalian Chondrocytes expanded in the presence of fibroblast growth factor 2 Maintain the ability to differentiate and regenerate three-dimensional cartilaginous tissue. Exp Cell Res 253: 681-688.

Narcisi R, Quarto R, Ulivi V, Muraglia A, Molfetta L, Giannoni $\mathrm{P}$ (2012) TGF $\beta$-1 administration during ex vivo expansion of human articular chondrocytes in a serum-free medium redirects the cell phenotype toward hypertrophy. J Cell Physiol 227: 3282-3290. 
Opolka A, Ratzinger S, Shubert T, Spiegel H-U, Grifka J, Bruckner P, Probst A, Grässel S (2007) Collagen IX is indispensable for timely maturation of cartilage during fracture repair in mice. Matrix Biology 26: 85-95.

Pec MK, Reyes R, Sánchez E, Carballar D, Delgado A, Santamaría J, Arruebo M, Evora C (2010) Reticulated Vitreous Carbon: A Useful Material for Cell Adhesion and Tissue Invasion. Eur Cells Mater 20: 282-294.

Qi Y, Chen X, Jiang YZ, Cai HX, Wang LL, Song XH, Zou XH, Ouyang HW (2009) Local delivery of autologous platelet in collagen matrix simulated in situ articular cartilage repair. Cell Transplantation 18: 1161-1169.

Qi Y, Chao T, Xu K, Dai T, Yan W (2011) The restoration of full-thickness cartilage defects with mesenchymal stem cells (MSCs) loaded and cross-linked bilayer collagen scaffolds on rabbit model. Mol Biol Rep 39: 1231-1237.

Qi Y, Du Y, Li W, Dai X, Zhao T, Yan W. (2012) Cartilage repair using mesenchymal stem cell (MSC) sheet and MSCs-loaded bilayer PLGA scaffold in a rabbit model. Knee Surg Sports Traumatol Arthrosc doi: 10.1007/ s00167-012-2256-3.

Reyes R, Delgado A, Sánchez E, Fernández A, Hernández A, Evora C (2012) Repair of an osteochondral defect by sustained delivery of BMP-2 or TGF $\beta 1$ from a bilayered alginate-PLGA scaffold. J Tissue Eng Reg Med doi: $10.1002 /$ term. 1549 .

Rudert M (2002) Histological evaluation of osteochondral defects: Consideration of animal models with emphasis on the rabbit, experimental setup, follow-up and applied methods. Cells Tissues 171: 229-240.

Schmal H, Mehlhorn A, Stoffel F, Köstler W, Südkamp NP, Niemeyer P (2009) In vivo quantification of intraarticular cytokines in knees during natural and surgically induced cartilage repair. Cytotherapy 11: 10651075 .

Shao XX, Hutmacher DW, Tuan Ho S, Goh JCH, Lee EH (2006) Evaluation of a hybrid scaffold/cell construct in repair of high-load-bearing osteochondral defects in rabbits. Biomaterials 27: 1071-1080.

Sellers RS, Peluso D, Morris EA (1997) The Effect of Recombinant Human bone Morphogenetic Protein-2 (rhBMP-2) oh the Healing of Full-Thickness Defects of Articular Cartilage. J Bone Joint Surg 79: 1452-1463.

Sellers RS, Zhang R, Glasson SS, Kim HD, Peluso D, D'Augusta DA, Beckwith K, Morris EA (2000) Repair of Articular Cartilage Defects One Year After Treatment with Recombinant Human Bone Morphogenetic Protein-2 (rhBMP-2). J Bone Joint Surg 82A: 151-160.

Tokuhara Y, Wakitani S, Imai Y, Kawaguchi A, Fukunaga K, Kim M, Kadoya Y, Takaoka K (2010) Repair of experimentally induced large osteochondral defects in rabbit knee with various concentrations of Escherichia coli-derived recombinant human bone morphogenetic protein-2. Int Orthop 34: 761-767.
Wakitani S, Goto T, Pineda SJ, Young RG, Mansour JM, Caplan AI, Goldberg VM (1994) Mesenchymal cell-based repair of large, full-thickness defects of articular cartilage. J Bone Joint Surg Am 76: 579-592.

Wang W, Li B, Yang J, Xin L, Li Y, Yin H, Qi Y, Jiang Y, Ouyang H, Gao C (2010) The restoration of full-thickness cartilage defects with BMSCs and TGF-beta 1 loaded PLGA/fibrin gel constructs. Biomaterials 31: 8964-8973.

Yan H, Yu C (2007) Repair of full-thickness cartilage defects with cells of different origin in a rabbit model. Arthroscopy 23: 178-187.

Yang JW, de Isla N, Huselstein C, Sarda-Kolopp MN, Li N, Li YP, Jing-Ping OY, Stoltz JF, Eljaafari A (2006) Evaluation of human MSCs cell cycle, viability and differentiation in micromass culture. Biorheology 43: 489-496.

Yang HS, La WG, Bhang SH, Kim HJ, Im GI, Lee H, Park JH, Kim BS (2011) Hyaline cartilage regeneration by combined therapy of microfracture and long term bone morphogenetic protein-2 delivery. Tissue Eng Part A 17: 1809-1818.

Zhang W, Chen J, Tao J, Jiang Y, Hu C, Huang L, Ji J, Ouyang HW. (2013) The use of type 1 collagen scaffold containing stromal cell-derived factor- 1 to create a matrix environment conducive to partial-thickness cartilage defects repair. Biomaterials 34: 713-723.

\section{Discussion with Reviewer}

G. Dodge: Is there any evidence that the different conditions the authors tested can affect cell metabolism? Since the XTT (or MTT) assay measures cell viability based on the activity of mitochondrial enzymes, this aspect needs to be considered in the future.

Authors: No, there was no evidence that the growth conditions used in this work affected the (succinate) dehydrogenase system of the mitochondrial respiratory chain during the XTT assay. The various manufacturers of XTT assays describe its usefulness for cell quantification in response to GFs, cytokines, and nutrients but also to cytotoxic or growth inhibiting agents. Some of the latter affect apoptosis-related mitochondrial pathways and, thus, lead to cell death. To avoid direct interference of experimentally used agents during the assay, the medium is replaced by normal culture medium for incubation. Thus, the here used FGF-2, though not considered a potentially problematic molecule, was also eliminated in this routine procedure, and all samples were analysed in standardised conditions. Also, we did not observe materialinduced changes in medium $\mathrm{pH}$ during incubation for cell expansion. As almost no dead cells had been detected on the in vitro cultured scaffold layers, we did not consider a direct cytotoxic effect by the material. 